\title{
Exposure to vinyl chloride and angiosarcoma of the liver: a report of the register of cases
}

\author{
D FORMAN, ${ }^{1}$ B BENNETT, ${ }^{2}$ J STAFFORD, ${ }^{2}$ AND R DOLL ${ }^{1}$
}

From the Imperial Cancer Research Fund Epidemiology and Clinical Trials Unit, ${ }^{1}$ Radcliffe Infirmary, Oxford OX26HE, and Imperial Chemical Industries plc, ${ }^{2}$ Thornton Cleveleys, Blackpool FY5 4QD, UK

\begin{abstract}
The Association of Plastic Manufacturers in Europe maintains a register of all cases of angiosarcoma of the liver (ASL) resulting from exposure to vinyl chloride monomer (VCM). This register has recorded all known VCM related cases of the disease worldwide that have been histologically confirmed. Although likely to be incomplete, it is the most comprehensive tabulation of such cases available and, by the end of 1984, 118 men had been registered. The information from analysis of the cases currently on the register is used to make an approximate projection of the number of cases to be expected in the future. The conclusion from this projection is that the industry is reaching the halfway stage in the appearance of VCM related ASL.
\end{abstract}

The idea that vinyl chloride might cause cancer was first suggested by Viola in 1970 as a result of experiments in rats. ${ }^{1}$ This was subsequently confirmed by Maltoni in 1973 with his comprehensive series of experiments in rats, mice, and hamsters. ${ }^{2}$ Among the tumours that developed in these animals was the normally rare angiosarcoma of the liver (ASL). It was not, however, until three cases of ASL were observed in men who had been heavily exposed to vinyl chloride in a polyvinyl chloride (PVC) polymerisation plant in the United States that the reality of the hazard was generally accepted. ${ }^{3}$ ASL is normally so rare that only three or four cases occur each year in the whole of Britain (see below) so that the occurrence of three cases in a small group of industrial employees in the United States was, in itself, sufficient to justify the belief that the chemical caused the disease. If, however, any doubt has persisted it was soon dispelled by the steady accretion of new industrial cases and the finding that angiosarcomas and various other tumours could be produced in rats by levels of exposure that were appreciably less than those that had previously occurred in industry. ${ }^{4}$ Steps were therefore quickly taken in the mid-1970s to reduce the extent to which individuals could be exposed from levels of the order of several hundred ppm to $5 \mathrm{ppm}$ $\left(13 \times 10^{6} \mathrm{ngm} / \mathrm{m}^{3}\right)$ or less. ${ }^{5}$ This reduction followed

Received 25 February 1985

Accepted 25 March 1985 an earlier lowering of exposure levels in the mid-1960s after concern was expressed about the narcotic effects of vinyl chloride and the risk of it producing acro osteolysis. Before then exposure to some employees was often in the range of several thousand ppm. The rarity of ASL, even under conditions of heavys exposure, has made it difficult to study its epi:demiological characteristics ${ }^{6}$ and it seemed, therefore, that it might be of value to summarise the data that have been recorded in the register of cases that has been maintained by Imperial Chemical Industries plc on behalf of the Association of Plastics Manufacturers in Europe (APME). This tabulates information about all the cases of ASL known to have occurred in men exposed to vinyl chloride that have been reported by individual manufacturing companies, trade associations, and occupational health organisations in Europe, North America, and Japan. The register is, doubtless, incomplete. It includes,

Table 1 Numbers of vinyl chloride related cases of angiosarcoma of the liver by date of death

\begin{tabular}{lc}
\hline Period & No of deaths \\
\hline $1955-9$ & 2 \\
$1960-4$ & 4 \\
$1965-9$ & 9 \\
$1970-4$ & 23 \\
$1975-9$ & 46 \\
$1980-4$ & 31 \\
$1955-84$ & $115^{*}$ \\
\hline *Three men diagnosed in $1980-4$ were still alive at 1 January 1985
\end{tabular}

*Three men diagnosed in 1980-4 were still alive at 1 January 1985. 
Table 2 Numbers of vinyl chloride related cases of angiosarcoma of liver by age at diagnosis

\begin{tabular}{lc}
\hline Age (years) & No of cases \\
\hline $35-39$ & 11 \\
$40-44$ & 24 \\
$45-49$ & 17 \\
$50-54$ & 18 \\
$55-59$ & 20 \\
$60-64$ & 17 \\
$65-69$ & 8 \\
$70-74$ & 3 \\
All ages & 118 \\
\hline
\end{tabular}

however, all the cases known to the collaborating organisations and they will probably have been informed, in one way or another, about nearly all cases that have been diagnosed among the relevant groups of employees.

\section{Results}

Until the end of 1984, 118 men had been recorded as having vinyl chloride related ASL, of whom three were still alive on 1 January 1985 . All the cases had been confirmed histologically: 117 were reported to be hepatoangiosarcomas and one a cholangiosarcoma. No cases were recorded in women, but few women have been employed in manufacturing PVC.

Table 1 shows the breakdown of the cases by date of death. It should be noted that the register was begun in 1974 when vinyl chloride first became firmly established as a risk factor for ASL. Under-reporting is, therefore, less likely to be a problem after this date when special attention began to be paid to the disease. Table 2 gives the age distribution of the 118 men at the time of diagnosis. The mean age at diagnosis is $\mathbf{5 2}$. Table 3 gives the number of cases diagnosed and the number of PVC producing factories in each of the 12 countries reporting at least one case of ASL. Some countries have had cases in most of their factories (France, West Germany); others have had cases clustered in a small number of factories (United States, United Kingdom). Indeed, the United States has had 23 of its 33 cases in just two factories. Other countries that produce PVC but have not reported any cases are shown in table 4.

Table 5 shows the numbers of cases by time since first exposure and maximum exposure time possible. It seems that the incidence of ASL reaches a peak 20-29 years after first exposure but substantial numbers of cases may still occur after more than 30 years. The table also gives hypothetical numbers for expected new cases based on the distribution of cases in men who could have experienced the maximum latency period. These calculations show that the occurrence of vinyl chloride related ASL is not yet at the halfway stage and one might reasonably expect another 150 cases or so with an unknown number of further cases occurring 35 years or more after first exposure. Table 6 shows the principal occupations of the 118 affected men. At least $43 \%$ of the men (51/118) had been employed as autoclave cleaners, an occupation that has been thought to have necessitated the highest exposure to vinyl chloride monomer.

\section{Discussion}

The reassuring feature of these results is that the number of cases on the register is so small, and, in particular, that only 80 new cases have been diagnosed since 1975 , despite the large size of the industry.

In the decade 1975-84, 19 cases were registered from the United States and seven from the United Kingdom. In men aged over 15 about 3300 deaths a year are attributed to all types of liver cancer in the United States and about 550 a year in the United Kingdom. Many of these cancers are probably sec-

Table 3 Distribution of vinyl chloride related cases of angiosarcoma of liver by country. (Number of factories with three or more cases in parentheses)

\begin{tabular}{|c|c|c|c|c|c|}
\hline \multirow[t]{2}{*}{ Country } & \multirow[t]{2}{*}{ No of cases } & \multirow{2}{*}{$\begin{array}{l}\text { No of factories } \\
\text { reporting cases }\end{array}$} & \multicolumn{2}{|c|}{ Total No of factories making PVC } & \multirow[t]{2}{*}{ Capacity* in 1972} \\
\hline & & & Pre-1974 & Pre-1964 & \\
\hline $\begin{array}{l}\text { United States } \\
\text { W Germany } \\
\text { France } \\
\text { Canada } \\
\text { United Kingdom } \\
\text { Sweden } \\
\text { Italy } \\
\text { Yugoslavia } \\
\text { Czechoslovakia } \\
\text { Japan } \\
\text { Belgium } \\
\text { Norway } \\
\text { All countries reporting cases }\end{array}$ & $\begin{array}{r}35 \\
26 \\
18 \\
10 \\
9 \\
5 \\
4 \\
4 \\
2 \\
2 \\
2 \\
1 \\
118\end{array}$ & $\begin{array}{r}10(3) \\
6(3) \\
5(3) \\
1(1) \\
2(1) \\
1(1) \\
4(-) \\
1(1) \\
1(-) \\
1(-) \\
1(-) \\
1(-) \\
34(13)\end{array}$ & $\begin{array}{r}44 \\
9 \\
7 \\
4 \\
7 \\
2 \\
11 \\
3 \\
1 \\
31 \\
2 \\
1 \\
122\end{array}$ & $\begin{array}{r}28 \\
7 \\
5 \\
3 \\
4 \\
1 \\
7 \\
2 \\
1 \\
16 \\
1 \\
1 \\
76\end{array}$ & $\begin{array}{r}2090 \\
1155 \\
627 \\
88 \\
502 \\
105 \\
778 \\
60 \\
48 \\
1699 \\
195 \\
65 \\
9462\end{array}$ \\
\hline
\end{tabular}

*Capacity in kilotonnes pvc production a year (Information supplied by ICI and by recipients of the register). 
Table 4 Countries with PVC factories operational before 1974 with no cases reported to register

\begin{tabular}{|c|c|c|}
\hline \multirow[t]{2}{*}{ Country } & \multicolumn{2}{|c|}{ Total No of factories } \\
\hline & Pre-1974 & Pre-1964 \\
\hline \multicolumn{3}{|l|}{ Western Europe } \\
\hline Austria & 1 & 1 \\
\hline Finland & 1 & - \\
\hline Greece & 1 & - \\
\hline Holland & 2 & 1 \\
\hline Portugal & 1 & 1 \\
\hline Spain & 4 & 3 \\
\hline \multirow{2}{*}{\multicolumn{3}{|c|}{ Eastern Europe }} \\
\hline & & \\
\hline Bulgaria & 1 & - \\
\hline East Germany & 2 & 2 \\
\hline Hungary & 1 & 1 \\
\hline Poland & 2 & 1 \\
\hline Rumania & 5 & 4 \\
\hline USSR & 3 & 1 \\
\hline \multicolumn{3}{|l|}{ South America } \\
\hline Argentina & 3 & 3 \\
\hline Brazil & 2 & 2 \\
\hline Chile & 1 & - \\
\hline Colombia & 2 & - \\
\hline Mexico & 5 & 2 \\
\hline Peru & 1 & - \\
\hline
\end{tabular}

Source: Information supplied by ICI and by recipients of the register.

ondary liver cancers originating in other organs, particularly in men over 60 , but if this is ignored it appears that only about $0.06 \%$ of liver cancers in adult men in the United States $(19 / 3300 \times 10)$ are attributable to vinyl chloride and about $0.13 \%$ in Britain (7/550 × 10).

Two pieces of evidence suggest that an extremely high exposure to vinyl chloride may be needed to induce ASL. Firstly, the fact that so many of the cases were among men working as autoclave cleaners in which the highest exposures are thought to have occurred: it was in these jobs that employees some- times became faint and unconscious before the 1960s, when the main concern about vinyl chloride was its narcotic effect. Secondly, in some countries there is a remarkable clustering of cases into a small number of factories. This suggests that the working conditions and hygiene standards varied in different factories. Fifteen of the 16 Japanese and 19 of the 28 United States factories operating before 1964 have reported no cases, and it would be helpful if it could be shown that the exposures in these factories was appreciably less-unless, of course, the number of employees in these factories were all very small.

It is the rarity of this tumour that has enabled its rapid identification as an effect of exposure to vinyl chloride. Baxter et al have calculated that the background incidence of ASL in the United Kingdom is between two and seven cases a year-that is, cases unattributable to exposure to vinyl chloride or to thorotrast, the other established aetiological agent. ${ }^{7}$ That being so then the seven industrial.cases in the decade 1975-84 represent an increase in the national figures of between $10 \%$ and $35 \%$.

The mean induction period (time from first exposure to initial diagnosis) for the 118 cases is 22.6 years. Most cases have occurred 15 to 29 years after first exposure as is common with occupationally induced cancers. There are also, however, substantial numbers of cases occurring after longer time intervals, 18 having been diagnosed 30 or more years after first exposure. This means that new cases are likely to be diagnosed well into the 1990s even if it is assumed that exposures were significantly reduced in the mid-1960s when the first major improvements in standards of hygiene were made. The mean induction period of the cases currently on the register ( $22 \cdot 6$ years) must there-

Table 5 Cases of vinyl chloride related angiosarcoma of liver tabulated by years from first exposure to vinyl chloride to diagnosis and years to 31 December 1984 (maximum possible latent period). (Number of cases expected to occur shown in parentheses*)

Years from first exposure Years from first exposure to date of diagnosis

to 31 December 1984

$5-\quad 10-\quad 20-\quad 25-\quad 30-34 \quad$ Total within 35 or more
35 years

\begin{tabular}{|c|c|c|c|c|c|c|c|c|}
\hline $\begin{array}{c}\geqslant 35 \\
30-34 \\
25-29 \\
20-24 \\
15-19 \\
0-14 \\
\text { Total }\end{array}$ & $\frac{-}{-}$ & $\begin{array}{r}2 \\
1 \\
3 \\
4 \\
2 \\
12\end{array}$ & $\begin{array}{l}1 \\
4 \\
10 \\
15 \\
2(+7) \\
\overline{32}(+7)\end{array}$ & $\begin{array}{l}10 \\
12 \\
8 \\
2(+25) \\
0(+17) \\
-32(+42)\end{array}$ & $\begin{array}{l}12 \\
7 \\
4(+9) \\
0(+29) \\
0(+18) \\
\frac{2}{23}(+56)\end{array}$ & $\begin{array}{l}7 \\
3(+4) \\
0(+10) \\
0(+22) \\
0(+14) \\
\overline{10}(+50)\end{array}$ & $\begin{array}{c}32 \\
27(+4) \\
25(+19) \\
21(+76) \\
5(+56) \\
0(+?)+ \\
110(+155)\end{array}$ & $\begin{array}{l}8 \\
? \\
? \\
? \\
? \\
? \\
8(+?) \ddagger\end{array}$ \\
\hline
\end{tabular}

* Number of cases expected to occur calculated by comparing proportion of cases in relevant years since first exposure category for previous time periods with proportion in other categories-for example, for 25-29 years since first exposure and $25-29$ years maximum latency expected:

$\frac{(3+10+8)}{(2+1+10+1+4+12)} \times(12+7)=\frac{21}{30} \times 19=13.3$

As four cases have already been diagnosed, another nine may be expected.

+ Number of new cases to be expected among workers who had less than 15 years since first exposure at 31 December 1984 will be dependent on whether the hazard of vinyl chloride was eliminated in the late 1960s or in the mid-1970s. In the former instance no cases would be expected, in the latter a number approaching the 61 cases projected for those with $15-19$ years since first exposure by the end of 1984 .

$\ddagger$ It is virtually impossible to estimate the number of expected new cases 35 or more years after first exposure. 
Table 6 Recorded occupations among ASL cases on register

\begin{tabular}{lc}
\hline & $N o^{*}$ \\
\hline Production worker/operator & 69 \\
Autoclave cleaner & 51 \\
General maintenance/fitter & 8 \\
Other jobs & 11 \\
Unknown & 17 \\
& 156 \\
\hline
\end{tabular}

*As several employees have more than one job recorded for them, these numbers do not add up to 118 .

fore be expected to be materially increased with the passage of time.

Any method to assess the number of expected new cases is likely to be imprecise. Our method simply looks at the proportions of cases with different latent periods and makes projections based on the distribution of cases that have occurred within different periods of maximum possible latency. In the absence of any information about the numbers of exposed employees it is all that can be done. The results suggest that another 155 cases are likely to be diagnosed within 35 years after first exposure. Compared with the 110 cases in this category diagnosed so far, this means that the industry is approaching the halfway stage in the appearance of ASL. The calculation of 155 more cases within 35 years of first exposure assumes that the hazard was essentially eliminated in the late 1960 s. If it was not a further 50 or 60 cases (something slightly less than the number expected to have been induced in men who could have been observed for only 15 to 19 years by the end of 1984) must be added to the total.

Further cases must also be expected to occur 35 or more years after first exposure but it is, as yet, virtually impossible to estimate the number to be expected with any precision. It could, however, easily be around 50 . We suggest, therefore, that it should be assumed that there will be another 200-250 deaths from vinyl chloride related ASL over the next 30 years. This estimate is in pronounced contrast with that calculated by Nicholson et al who suggest that "within a factor of 2 or 3" there will eventually be a total of 350 deaths from vinyl chloride related ASL in the United States and 1200 in Western Europe alone. ${ }^{8}$ Nicholson et al used a complex model to deduce these figures based on the assumption that the incidence of
ASL at any point in time increases in proportion to (i) the first power of the product of the population at risk and the degree of exposure and (ii) a higher power (most probably the third) of the time since exposure first occurred. ${ }^{8}$ Knowledge of the distribution of cases recorded by the National Institute of Occupational Health and Hygiene (1982) by year of first exposure and year of occurrence, the amount of vinyl chloride produced, estimated average exposures at work at different periods from before 1950 to $1970-4$, and normal national mortality rates allowed them to make approximate estimates of the variables in these equations and hence to calculate the number of cases that might be expected to occur in the future.

Only time will show which of the two methods will give the better estimate of the number of cases that will eventually be observed. We are encouraged, however, to think that the lower estimate may be the nearer as the method of Nicholson et al predicted an increase in the annual number of cases after 1979, whereas the number recorded to date has declined from an average of 9.2 in 1975-9 to an average of 6.8 in 1980-4. The latter figures will, however, almost certainly, be revised upwards in the course of the next few years owing to delayed reporting.

\section{References}

1 Viola PL. Pathology of vinyl chloride. Med Lav 1970;61:174:80.

2 Maltoni C. Occupational carcinogenesis 2nd International Symposium on Cancer Detection and Prevention, Bologna, 1974. In: Advances in tumour prevention, detection, and characterisation. Vol 2. Amsterdam: Excepta Medica, 1977.

${ }^{3}$ Creech JL, Johnson MW. Angiosarcoma of the liver in the manufacture of PVC. J Occup Med 1974;16:19-26, 150-1.

4 Maltoni C, Lefemine G. Carcinogenicity bioassays of vinyl chloride. Environ Res 1974;7:387-405.

5 Barnes AW. Vinyl chloride and the production of PVC. Proceedings of the Royal Society of Medicine 1976;69:277-80.

${ }^{6}$ Fox AJ, Collier PF. Mortality experience of workers exposed to vinyl chloride monomer in the manufacture of polyvinyl chloride in Great Britain. Br J Ind Med 1977;34:1-10.

7 Baxter PJ, Anthony PP, MacSween RNM, Schauer PJ. Angiosarcoma of the liver: incidence and aetiology in Great Britain. $B r$ $J$ Ind Med 1980;37:213-21.

${ }^{8}$ Nicholson WJ, Henneberger PK, Tarr D. Trends in cancer mortality among workers in the synthetic polymers industry. In: Industrial hazards of plastics and synthetic elastimers. New York: Lis, 1984:65-78. 